\title{
ESTIMATION OF GENETIC PARAMETERS AND BREEDING VALUES FROM SINGLE- AND MULTIPLE-TRAIT ANIMAL MODELS ANALYSES FOR FRIESIAN CATTLE IN EGYPT Oudah, E. Z. M. \\ Department of Animal Production, Faculty of Agriculture, Mansoura University, PC: 35516, Mansoura, Egypt. E-mail: eoudah@uoguelph.ca
}

\begin{abstract}
The objectives of this study were to estimate genetic parameters and breeding values for some productive, reproductive and growth traits of Friesian cows by using univariate and multivariate animal models analyses. Data on 305-day milk yield (305-dMY), lactation period (LP), number of services per conception (NOS), age at first calving (AFC), birth weight of calf (BW) and weaning weight of calf (WW) from 1011 first lactation records of Friesian cows daughters of 705 dams and 103 sires for a period of 19 years (1977 to 1995) were used to estimate genetic parameters and breeding values. Single- and multi-trait heritability animal models were used to estimate parameters based on restricted maximum likelihood methodology. Fixed effects in the model varied depending on the individual trait. Single-trait analysis of 305-dMY, LP, NOS, AFC, BW and WW, was investigated as a method to genetic parameters and breeding values for individual traits. Multiple-trait analysis (four traits) including 305-dMY, LP, NOS and AFC; and multiple-trait analysis (two traits) included BW and WW were performed. Statistical Analysis System (SAS) was utilizing to investigate the effect of fixed effects on these traits using mixed model procedure. The overall means ( \pm standard deviations) of 305-dMY, LP, NOS, AFC, BW and WW were $2737 \pm 25.6 \mathrm{~kg}, 334 \pm 112$ day, $2.28 \pm 1.86$ service, $31.8 \pm 5.84$ months, $29.0 \pm 4.25$ and $95.6 \pm 9.40 \mathrm{~kg}$, respectively. Minor differences in Heritability estimates $\left(\mathrm{h}^{2}\right)$ obtained from single versus multi-trait animal model analyses for most studied traits. Heritability estimates for single-traits analysis were $0.27,0.12,0.04,0.25,0.19$ and 0.06 for 305-dMY, LP, NOS, AFC, BW and WW, respectively. Meanwhile, $\mathrm{h}^{2}$ for multiple-traits analysis were $0.28,0.03,0.04,0.31,0.04$ and 0.10 for $305-d M Y, L P$, NOS, AFC, BW, WW, respectively. Genetic correlations $\left(r_{G}\right)$ of 305-dMY and each of fertility traits (NOS and AFC) were unfavourable (0.49 and 0.39 , respectively), between NOS and AFC was 0.97 and between BW and WW was 0.71 suggesting that 305-dMY could be considered in a fertility index. However, there were important differences in breeding value predictions for the same trait between single- and multiple-trait analyses. Breeding values for all animals regarding 305-dMY ranged from -3.43 to 5.62 and -4.38 to $7.67 \mathrm{~kg}$ for single versus multiple-trait analyses, respectively. The corresponding values for AFC were -4.01 to 7.94 and -3.92 to 6.94 months, respectively. It is recommended that selecting for milk production alone would lead to decline in genetic merit for fertility traits considered here, where milk production has antagonistic $r_{G}$ with NOS. Results of genetic correlations suggest that because of single-trait method is biased due to selection for 305-dMY, a multiple-trait analysis is recommended for production and reproduction traits if all traits are recorded. The genetic parameters estimated from field test records allow to achieve genetic progress in 305-dMY and AFC of Friesian cattle.
\end{abstract}

Keywords: dairy cattle, MTDFREML, productive traits, reproductive traits, growth traits, genetic and phenotypic correlations, Friesian calves 
Oudah, E. Z. M.

\section{INTRODUCTION}

In Egypt, Friesian cattle play a great role in dairy industry because of its high productivity of milk compared with the local cattle. The genetic parameters for a trait, which are calculated from variances and covariances obtained in statistical analyses of phenotypic records, are essential in animal breeding. Genetic parameters are also needed to predict breeding values to be used in the ranking and selection of superior animals for breeding. These parameters are only valid in a certain population, can change with time, and should therefore be re-estimated regularly. Consequently, estimation of genetic parameters for productive and reproductive traits and breeding values of Friesian cattle in Egypt are required for the genetic improvement programs of these cattle.

Age at first calving and first lactation milk yield are expected to contribute a good deal towards the producing capacity of an animal during her life and consequently needs an important consideration in selecting cows (Gopal and Bhatnagar, 1972). Several studies (e.g. Royal et al., 2002 and Haile-Mariam et al., 2003) reported that the genetic correlation between fertility and milk production traits is antagonistic. Schaeffer (1984) mentioned that a multi-trait analysis of fertility with milk yield as an additional trait is a different approach which aims to improve accuracy of genetic evaluations for the traits involved by reducing variances of prediction error of estimated breeding values. Additionally, dairy cattle are commonly observed for more than one trait because many traits affect overall profitability. Misztal et al (1993) reported that for improving the accuracy of its genetic evaluations, the Holstein Association of America has changed from a sire model to an animal model. The same authors concluded that a multiple-trait evaluation may be performed, given certain assumptions about the (co)variance matrices. A multiple trait model is one in which two or more traits are analyzed simultaneously in order to take advantage of genetic and environmental correlations between traits.

One of the most important practices in animal breeding strategies is to find more accurate and practical models for estimating genetic and environmental parameters. Animal models are more suitable than sire models because of considering all pedigree relationships rather than only sire lines. Accordingly, The main objectives of the this study were: 1) To estimate the genetic parameters and breeding values of some productive (305-dMY and $\mathrm{LP}$ ), reproductive (NOS and AFC) and growth (BW and WW) traits and 2) to compare $\mathrm{h}^{2}$ and breeding values obtained by using single- and multi-trait animal model analyses for the same traits for a governmental herd of Friesian cow in Egypt.

\section{MATERIALS AND METHODS}

\section{Data and management}

Data on 305-day milk yield (305-dMY), lactation period (LP), number of services per conception (NOS), age at first calving (AFC), birth weight of 
calf (BW) and weaning weight of calf (WW) from 1011 first lactation records of Friesian cows daughters of 705 dams and 103 sires for a period of 19 years (1977 to 1995) belonging to Sakha Animal Production Research Station, Animal Production Research Institute, Ministry of Agriculture situated at Kafrelsheikh Governorate in the northern part of Nile Delta of Egypt were used to estimate genetic parameters and breeding values. Single- and multitrait heritability animal models were used to estimate parameters based on restricted maximum likelihood methodology.

Cows were artificially inseminated at random. Heifers were serviced for the first time when reached 18 months of age or $350 \mathrm{~kg}$ live body weight which come first. Cows were usually served two months postpartum. Pregnancy was detected by rectal palpation 60 days after last mating. The cows were loosely housed in open sheds system. Cows were kept under similar system of feeding and management practiced on the farm applied by Animal Production Research Institute, Ministry of Agriculture. All cows were fed on good quality concentrate ration. During winter and spring months (from December to May), animals were supplied with Egyptian clover (Trifolium alexandrinum), while during summer and autumn (from June to November), animals were fed on dry ration, mainly either Egyptian cover hay or green sweet sorghum. Also, rice straw was available around the year. Feeds were supplied to cows according to their live body weight, milk production and pregnancy status. Portable water and mineral mixture were available freely. Cows were machines milked twice daily in a parallel. Cows were usually dry off about two months before the expected calving date.

Friesian calves were allowed to suckle their dam's colostrums for the first three days after birth, thereafter they were artificially reared on natural milk twice daily on the age basis till weaning at the age of $15 \mathrm{wk}$. An amount of $500 \mathrm{~kg}$ of natural milk was available for each calf during the suckling period. Beside milk, green fodder was given to the calves ad libitum according to the schedule applied under the feeding and management system of Animal Production Research Institute, Egypt. Green fodder in winter was Egyptian clover (Trifolium alexandrinum) and green maize or elephant grass were offered in summer. The calf meal (concentrates) and hay were offered to calves from the beginning of the third week of age according to their live body weight. Calves were weighed for the first time within 24 hours from birth and also at weaning at 15 weeks of age.

\section{Genetic Evaluation}

Genetic parameters included heritability, phenotypic and genetic correlations and breeding values for evaluated traits were estimated under a single- or multiple-trait model, with fixed effects of year of calving/birth and season of calving/birth. Age at first calving, body weight at calving, sex of calf and/or total milk yield were used as covariates with a random animal effect. Fixed effects in the model varied depending on the individual trait. A list of dependent variables (studied traits) and independent variables (additive genetic, fixed effects and covariates) used in the statistical models for singleand multi-trait analyses is given in Table 1. 
Oudah, E. Z. M.

Table 1: A list of dependent variables (studied traits) and independent variables (additive genetic, fixed effects and covariates) used in the statistical models for single- and multi-trait analyses.

\begin{tabular}{|c|c|c|c|c|c|c|c|}
\hline \multirow[t]{2}{*}{ Trait } & \multirow{2}{*}{$\begin{array}{c}\text { Additive } \\
\text { Genetic effect }\end{array}$} & \multicolumn{3}{|c|}{ Fixed effect } & \multicolumn{3}{|c|}{ Covariates } \\
\hline & & $\mathbf{Y r}$ & Sea & Sex & LWC & TMY & AFC \\
\hline \multicolumn{8}{|c|}{ Single-trait animal model } \\
\hline 305-dMY & $\mathrm{x}$ & $x$ & $x$ & & $x$ & & $x$ \\
\hline LP & $\mathrm{x}$ & $\mathrm{x}$ & $\mathrm{x}$ & & $\mathrm{x}$ & & $\mathrm{x}$ \\
\hline NOS & $\mathrm{x}$ & $x$ & $\mathrm{x}$ & & $\mathrm{x}$ & $\mathrm{x}$ & \\
\hline AFC & $\mathrm{x}$ & $x$ & $x$ & & & & \\
\hline BW & $\mathrm{x}$ & $x$ & $x$ & $\mathrm{x}$ & $\mathrm{x}$ & & \\
\hline WW & $x$ & $X^{*}$ & $x$ & $x$ & $x$ & & \\
\hline \multicolumn{8}{|c|}{ Multi-trait animal model for productive and reproductive traits (four traits) } \\
\hline 305-dMY & $x$ & $\mathrm{x}$ & $x$ & & $\mathrm{x}$ & & $\mathrm{x}$ \\
\hline LP & $\mathrm{x}$ & $\mathrm{x}$ & $x$ & & $\mathrm{x}$ & & $\mathrm{x}$ \\
\hline NOS & $\mathrm{x}$ & & & & $x$ & $\mathrm{x}$ & \\
\hline AFC & $x$ & $\mathrm{x}$ & $x$ & & & & \\
\hline \multicolumn{8}{|c|}{ Multi-trait animal model for growth traits (two traits) } \\
\hline BW & $x$ & $x$ & $\mathrm{x}$ & $\mathrm{x}$ & $\mathrm{x}$ & & \\
\hline WW & $x$ & $\mathrm{x}$ & $x$ & $\mathrm{x}$ & $x$ & & \\
\hline
\end{tabular}

305-dMY= 305-day milk yield, LP = lactation period, NOS = number of services per conception, $A F C=$ age at first calving, $B W=$ birth weight, $W W=$ weaning weight, $\mathrm{Yr}=$ year of calving, Sea = season of calving/birth, Sex = sex of calf, LWC = live weight of cow/dam at calving and AFC = age at first calving. *1982-1995 only

Statistical Analysis System (SAS, 2004) was utilizing to investigate the effect of fixed effects on these traits using mixed model procedure. The statistical analyses were performed using Multivariate Derivative Free Restricted Maximum Likelihood (MTDFREML) program of Boldman et al. (1995) to estimate the genetic parameters and breeding values. Models used for single- and multiple-trait evaluations were as follows:

$$
Y_{i j k l}=\mu+A_{i}+Y j+S_{k}+B_{X}+e_{i j k l}
$$

Where, $Y$ is an observation of the studied trait, $\mu$ is overall mean, $A_{i}$ is the random additive genetic effect of $i^{\text {th }}$ animal, $Y_{j}$ is the fixed effect of $I^{\text {th }}$ year of calving $(k=1,2,3, \ldots .19) 1=1977,2=1978 \ldots . .19=1995, S$ is the fixed effect of $t^{\text {th }}$ season of calving/birth $(I=1,2,3$, and 4) $1=$ Winter..... 4= Autumn, $B$ is the regression coefficient which is different according to the analyzed trait (x) as given in Table 1, and $e_{\mathrm{ijklm}}$ is measurement error. Initial analyses of each trait were conducted using a single trait animal model. Sex of the calf was added as fixed effect in case of both BW and WW analyses. Year of calving in case of WW were from 1982 to 1995. The vector presentation of this model is:

$$
\mathrm{Y}=\mathrm{Xb}+\mathrm{Zu}+\mathrm{e}
$$

Where: $Y=$ observations vector of records, $\beta=$ the vector of fixed effects, $a=$ the vector of direct genetic effects and $e=$ the vector of residual effects. $X$ and $Z$ are incidence matrices relating records to fixed and direct genetic, respectively. Estimates of additive direct heritability $\left(h^{2} a\right)$ were calculated as follows:

$$
h^{2} a=\sigma^{2} a /\left(\sigma^{2} a+\sigma^{2} e\right)
$$

Where: $\sigma^{2} \mathrm{a}$ is the additive direct genetic variance, $\sigma^{2} \mathrm{e}$ is the random residual effect associated with each observation. 
Mixed-model equations (MME) in the analyses were solved iteratively. Based on the variance of the log-likelihood function values, the convergence criterion was $1 \times 10^{-9}$. In addition, several restarts were necessary until changes in the log-likelihood function values (-2log $\mathbf{L})$ were less than $1 \times 10^{-5}$. Restarts were performed for all analyses, using the final results of the previous analysis, in order to locate the global maximum for the log likelihoods. Starting values for variance components for single-trait analyses were obtained from literature. And starting values for variance components for multi-trait analyses were obtained from single-trait analyses on individual traits. Best linear unbiased prediction (BLUP) of estimated breeding values (EBVs) was obtained by back-solution using the MTDFREML program for all animals in the pedigree file for single-trait and multi-trait animal model analyses. Spearman rank correlations and Pearson correlation coefficients among EBVs for traits studied obtained from single-trait and multi-trait analyses were estimated using SPSS (1999) program. Data structure used in the statistical analyses is listed in Table 2.

Table 2: Data structure used in the statistical analyses

\begin{tabular}{lcccccc}
\hline Data set description & 305-dMY & LP & NOS & AFC & BW & WW \\
\hline Total number of records & 1011 & 1011 & 1011 & 1011 & 1011 & 1011 \\
Total number of valid records & 528 & 940 & 902 & 1011 & 915 & 451 \\
Total number of records with missing values & 483 & 71 & 109 & --- & 96 & 560 \\
Number of animals with valid records & 528 & 940 & 902 & 1011 & 915 & 451 \\
Number of animal in A-1 & 1804 & 1804 & 1804 & 1804 & 1804 & 1804 \\
Order of MME & 1831 & 1831 & 1831 & 1831 & 1831 & 1826 \\
\hline
\end{tabular}

305-dMY= 305-day milk yield, LP = lactation period, NOS = number of services per conception, $A F C=$ age at first calving, $B W=$ birth weight, $W W=$ weaning weight.

\section{RESULTS AND DISCUSSION}

\section{Descriptive statistics}

Overall means, standard deviations (SD), minimum and maximum for six traits under investigation are shown in Table 3. The overall means $( \pm$ standard deviations) of 305-dMY, LP, NOS, AFC, BW and WW were $2737 \pm 25.6 \mathrm{~kg}, 334 \pm 112$ day, $2.28 \pm 1.86$ service, $31.8 \pm 5.84$ months, $29.0 \pm 4.25$ and $95.6 \pm 9.40 \mathrm{~kg}$, respectively. Generally, the overall means of the studied traits are in the range of the same traits obtained on Friesian cows in Egypt reported in the literature. For example, the mean of 305-dMY reported in the present study $(2737 \mathrm{~kg})$ was in close agreement with that $(2722 \mathrm{~kg})$ obtained by El-Sheikh (1995) working with another set of Friesian cows at the same farm (Sakha Station). Lower values of 305-dMY than that reported in the present study were found by Ashmawy and Khalil (1990) (4295 kg), Shalaby et al. (2001) (2995 kg), Atil and Khattab (2005a) (4642 $\mathrm{kg})$. Shalaby (2005) $(5546 \mathrm{~kg})$ working on Friesian cows in a commercial herd in Egypt and El-Awady and Oudah (2009) $(3639 \mathrm{~kg})$. Lower values of 305dMY than that reported in the present study was reported by Abdel-Glil (1996) $(2461 \mathrm{~kg})$.

Regarding the reproductive performance reported in the present study (NOS and AFC), Hammoud et al (2009) working on governmental 
Oudah, E. Z. M.

Friesian cattle in Egypt belonging to Faculty of Agriculture, Alexandria University. They found that the overall least squares means ( \pm standard error) of NOS and AFC were $2.1 \pm 0.1$ service and $30.7 \pm 0.1$ months, respectively which is nearly similar to those reported in the present study. Similar estimate of NSC (2.0 services) was reported by Kassab and Salem (1993). High NOS results from either failure to conceive at a given service and/or failure to maintain pregnancy thus requiring repeated service (Hammoud et al., 2009). Result of Hammoud et al. (2009) on Friesian cattle in a governmental herd in Egypt concerning AFC (30.7 months) was in agreement with those reported in the present study (31.8 months). On the other hand, AFC reported here is higher than that reported by Shalaby (2005) (27.7 months) working on Friesian cattle in a commercial herd in Egypt reflecting the good management in the commercial farms comparing with governmental farms.

Concerning growth traits, the overall mean ( \pm standard deviation) of BW $(29.0 \pm 4.25 \mathrm{~kg})$ and WW $(95.6 \pm 9.40 \mathrm{~kg})$ reported in the present study were also fall within the range of those estimates reported in most studies carried out on the Friesian calves under Egyptian conditions ranged between 25.9 to $37.3 \mathrm{~kg}$ for BW and between 76.2 to $98.0 \mathrm{~kg}$ for WW (Oudah, 2002). The previous author (Oudah, 2002) working on another set of Friesian calves in Egypt found that the means for BW and WW were $31.5 \pm 4.46$ and $96.6 \pm 9.25 \mathrm{~kg}$, respectively. Atil et al (2005) using Friesian calves also in Egypt found that means of BW and WW were $31.8 \pm 4.58$ and $97.2 \pm 10.3 \mathrm{~kg}$, respectively. The coefficient of variations (CV \%) of BW (14.6\%) and WW (9.83\%) obtained in the present study were in close agreement with the findings of Oudah (2002) being 14.2 and $9.58 \%$ and Atil et al. (2005) being 14.4 and $10.5 \%$ for BW and WW, respectively. The present results (Table 3 ) revealed that some of the productive and reproductive had high coefficients of variation ranged from $9.83 \%$ (for WW) to $82.0 \%$ for NOS. Such large coefficients of variation are indicative leaders for opportunities for improvement in these traits. The differences between our findings and other investigators may be related to genetic differences between breeds, climatic conditions, differences in statistical models, managerial practices and/or feeding system that would affect live body weights.

Table 3: Mean, standard deviation (SD), coefficient of variation (CV\%), minimum and maximum for studied traits

\begin{tabular}{lccccc}
\hline Trait & Mean & SD & C.V (\%) & Min. & Max. \\
\hline \multirow{2}{*}{ 305-day milk yield (kg) } & Productive trait & & & & \\
Lactation period (day) & 2737 & 702 & 25.6 & 1051 & 5431 \\
& 334 & 112 & 33.5 & 100 & 925 \\
No. of services per conception & Reproductive trait & & & \\
Age at first calving (month) & 2.28 & 1.86 & 82.0 & 1.00 & 10.0 \\
& 31.8 & 5.84 & 18.4 & 20.0 & 64.5 \\
Birth weight of calf (kg) & Growth traits & & & & \\
Weaning weight of calf $(\mathrm{kg})$ & 29.0 & 4.25 & 14.6 & 19.0 & 46.0 \\
\hline
\end{tabular}

\section{Genetic parameters}

Heritability

Heritability estimates and their standard errors for studied traits obtained from single- and multi-trait genetic analyses during the first lactation 
of Friesian cows are shown in Table 4. Heritability estimates for single-traits analysis were $0.27,0.12,0.04,0.25,0.19$ and 0.06 for 305-dMY, LP, NOS, AFC, BW and WW, respectively. Heritability estimates for multiple-traits analysis were $0.28,0.03,0.04,0.31,0.04$ and 0.10 for $305-\mathrm{dMY}$, LP, NOS, AFC, BW, WW, respectively. Minor differences were observed in heritabilities of some traits obtained from single versus multi-trait animal model analyses. Similar findings have also been reported by Costa et al. (2000), Kadarmideen et al. (2003) and Shalaby (2005).

Table 4. Estimates of variance components and heritability ( \pm standard error) for studied traits derived by the single- and multi-trait animal model

\begin{tabular}{|c|c|c|c|c|}
\hline traits & Genetic variance & $\begin{array}{c}\text { Environmental } \\
\text { variance }\end{array}$ & $\begin{array}{c}\text { Phenotypic } \\
\text { variance }\end{array}$ & $\begin{array}{l}\text { Heritability } \\
\text { ( } \pm \text { SE) }\end{array}$ \\
\hline \multicolumn{5}{|c|}{ Single-trait animal model } \\
\hline 305-dMY & 8.39 & 22.6 & 31.0 & $0.27 \pm 0.154$ \\
\hline LP & 14.0 & 104.9 & 118.9 & $0.12 \pm 0.072$ \\
\hline NOS & 0.115 & 2.64 & 2.75 & $0.04 \pm 0.064$ \\
\hline AFC & 7.86 & 23.4 & 31.2 & $0.25 \pm 0.097$ \\
\hline BW & 2.72 & 11.7 & 14.4 & $0.19 \pm 0.085$ \\
\hline WW & 4.87 & 81.6 & 86.4 & $0.06 \pm 0.104$ \\
\hline \multicolumn{5}{|c|}{ Multi-trait animal model } \\
\hline 305-dMY & 12.4 & 32.4 & 44.9 & $0.28 \pm 0.110$ \\
\hline LP & 3.18 & 123 & 126 & $0.03 \pm 0.011$ \\
\hline NOS & 0.13 & 2.90 & 3.02 & $0.04 \pm 0.053$ \\
\hline AFC & 8.18 & 18.6 & 26.8 & $0.31 \pm 0.067$ \\
\hline BW & 3.90 & 106 & 110 & $0.04 \pm 0.091$ \\
\hline WW & 9.87 & 90.2 & 100 & $0.10 \pm 0.121$ \\
\hline
\end{tabular}

305-dMY=305-day milk yield, LP=lactation period, NOS=number of services per conception, $A F C=a g e$ at first calving, BW=birth weight, WW=weaning weight, heritability = genetic variance/phenotypic variance.

The moderate $\mathrm{h}^{2}$ of $305-\mathrm{dMY}$ obtained from single-trait $(0.27)$ or from multi-trait (0.28) analysis fall within the range of estimates reported by different authors working on Friesian cattle in Egypt (e.g. Abdel-Glil, 1996; Badawy and Oudah, 1999: Khattab et al., 2000: El-Arian et al., 2003: Atil and Khattab (2005a) and (2005b): Shalaby, 2005 and El-Awady and Oudah, 2009) ranged from 0.12 to 0.52 . Single-trait analysis of the data gave an estimate of $0.25 \pm 0.097$ for the $h^{2}$ of AFC which was lower than that obtained from multi-trait analysis $(0.31 \pm 0.067)$. The $\mathrm{h}^{2}$ reported here fall within the range of some reported estimates by different authors ranged from 0.05 (Seykora and McDaniel, 1983) to 0.75 (Atil and Khattab, 2005a). Shalaby (2005) found that $h^{2}$ of AFC from single- and two-trait animal model analyses were $0.19 \pm 0.075$ and $0.18 \pm 0.056$, respectively. The moderate $h^{2}$ reported here for 305-dMY and AFC, are enough to allow genetic improvement in these traits which could be achieved through selection.

In spite of the single trait analysis gave higher $\mathrm{h}^{2}$ for LP comparing with multi-trait analysis $(0.12 \pm 0.072$ versus $0.03 \pm 0.011)$, the two estimates were low. El-Arian et al (2003) and Atil and Khattab (2005b) obtained $\mathrm{h}^{2}$ of 0.07 . The $h^{2}$ of NOS obtained from single and multi-trait analyses were 
Oudah, E. Z. M.

similar and low (0.04). Oudah et al (2001) obtained $\mathrm{h}^{2}$ of 0.11 on HolsteinFriesian. Heritability estimate of BW obtained from single-trait analysis was higher than that obtained from multi-trait analysis $(0.19 \pm 0.085$ versus $0.04 \pm 0.091$ ), meanwhile, there was minor difference between WW values $(0.06 \pm 0.104$ versus $0.10 \pm 0.121$, for single- and multi-trait analysis, respectively). Higher $\mathrm{h}^{2}$ ( \pm standard error) for $\mathrm{BW}$ and $\mathrm{WW}$ were obtained by Oudah and Mehrez (2000) being 0.24 to 0.27 , Atil et al. (2005) working on Friesian cattle in Egypt being $0.28 \pm 0.10$ and $0.13 \pm 0.09$ for the two traits, respectively. Oudah and El-Awady (2006) also, found that $\mathrm{h}^{2}$ of BW and WW were $0.24 \pm 0.08$ and $0.28 \pm 0.08$, respectively. The differences between present results and other investigators may be due to differences in the genotypes, management, and number of records and/or methods of analysis. The low $\mathrm{h}^{2}$ of some traits studied indicated that the major part of the variation in these traits was environmental and selection may not prove effective in bringing about genetic improvement in these traits. Therefore, better management can play a major role in improving these traits.

\section{Genetic and phenotypic correlations}

Estimates of genetic and phenotypic correlations among first lactation traits with multi-trait animal model analysis are shown in Table 5. Genetic correlations $\left(r_{G}\right)$ of 305-dMY and each of fertility traits (NOS and AFC) were unfavourable ( 0.49 and 0.39 , respectively), between NOS and AFC was 0.97 and between BW and WW was 0.71 suggesting that $305-\mathrm{dMY}$ could be considered in a fertility index. The $r_{G}$ between 305-dMY and NOS indicated that higher-yielding animals were associated with more services to conceive and hence longer calving intervals. The main reason for the antagonistic of milk yield with reproduction and health traits is assumed to that cows produce at a maximum level when they are expected to show oestrous conceives (Shalaby, 2005). The effect of high milk production on the incidence of reproductive disorders may be related to the degree to which energy balance becomes negative in the early lactation. During early lactation, the high producing cows are unable to consume enough feed to meet their energy requirements and these cows become in negative energy balance, which could result in reduced reproductive performance (Gröhn et al., 1994). Pryce et al. (1998) concluded that when selecting for milk yield alone, the $\mathrm{Cl}$ prolong by 5 to 10 days per $1000 \mathrm{~kg}$ milk. It is recommended that selecting for milk production alone would lead to decline in genetic merit for fertility traits considered here, where milk production has antagonistic $r_{g}$ with NOS. Consequently, Sire and cow evaluations must be calculated and incorporated into a multi-trait selection index by a combination of production and fertility traits (Shalaby, 2005). The positive genetic (0.39) and phenotypic (0.57) correlations between 305-dMY and AFC indicated that older heifers at first calving are superior in milk production. Ojango and Pollott (2001) found that the genetic correlation between the two traits was high and positive (0.54). However, Atil and Khattab (2005a) reported that the genetic correlation between $305-d M Y$ and AFC was negative (-0.22). They suggested that 
selection for high yielding cows would cause a correlated decrease in their AFC.

The positive genetic (0.71) and phenotypic (0.37) correlations between BW and WW indicated that the two traits are defined by similar genes. Steinhardt and Thielscher (2000) Lengyel et al. (2001) working on Simmental calves, found that phenotypic and genetic correlations between birth and weaning weights were 0.90 and 0.89 , respectively. Oudah (2002) using another set of Friesian cow in Egypt found that Phenotypic and genetic correlations between birth and weaning weights were 0.147 and 0.185 , respectively utilizing another statistical program. Atil et al. (2005) found that phenotypic and genetic correlations between BW and WW in Friesian calves in Egypt were 0.80 and 0.89 , respectively utilizing MTDFREML methodology.

Table 5. Estimates of genetic (above diagonal) and phenotypic (below diagonal) correlations between analyzed traits obtained from Multi-trait animal model analysis

\begin{tabular}{|l|c|c|c|c|c|c|}
\hline Trait & $305-d M Y$ & LP & NOS & AFC & BW & WW \\
\hline 305-dMY & -- & 0.18 & 0.49 & 0.39 & & \\
\hline LP & 0.43 & -- & 0.31 & 0.52 & & \\
\hline NOS & 0.40 & 0.20 & -- & 0.97 & & \\
\hline AFC & 0.57 & 0.24 & 0.55 & -- & & \\
\hline BW & & & & & -- & 0.71 \\
\hline WW & & & & & 0.37 & -- \\
\hline
\end{tabular}

305-dMY=305-day milk yield, LP=lactation period, NOS=number of services per conception, $A F C=$ age at first calving, $B W=$ birth weight, $W W=$ weaning weight

\section{Estimated breeding values}

Minimum, maximum, standard deviation (SD) and percentage of negative estimates for breeding values obtained from single- and multi-trait animal model analyses for different studied traits $(n=1804)$ are presented in Table 6.Regarding the breeding values obtained from single-trait analysis, the range of all animals in the pedigree for 305-dMY, LP, NOS and AFC were $9.06 \mathrm{~kg}, 9.85$ day, 0.69 service and 11.9 months, respectively. Meanwhile, the ranges of multi-trait analysis were $12.1 \mathrm{~kg}, 4.67$ day, 1.30 services and 10.9 month, for the same traits, respectively. Generally, the percentages of negative breeding values obtained from single-trait analysis were lower than those obtained from multi-trait analysis, being $44.5,53.7$, and $50.2 \%$ versus 55.5, 55.0 and $55.9 \%$ for $305-\mathrm{dMY}$, LP and NOS, respectively. However, minor difference in percentage of negative breeding value of AFC between single and multi-trait analysis (56.8 versus $55.8 \%$ ). The present results indicated that there was wide range of breeding values for all studied traits, suggests the existence of genetic variation between animal and hence the possibility of sire selection using multi-trait traits evaluation for fertility traits with milk yield. Atil and Khattab (2005b) found that the range of cow, sire and dam breeding values of AFC were 17.94, 14.31 and 9.09 month, respectively. Atil and Khattab (2005a) found that the range of sire breeding value for AFC was 14.3 months. 
Oudah, E. Z. M.

Table 6: Minimum, maximum, standard deviation and negative estimates percentage for breeding values obtained from single- and multi-trait animal model analyses for different studied traits (all animals in the pedigree, $n=1804$ ).

\begin{tabular}{|l|c|c|c|c|c|}
\hline Trait & min & max & range & SD & Negative \% \\
\hline \multicolumn{7}{|c|}{ Single-trait animal model } \\
\hline 305-dMY (kg) & -3.43 & 5.62 & 9.06 & 1.01 & 44.5 \\
\hline LP (day) & -3.41 & 6.44 & 9.85 & 1.30 & 53.7 \\
\hline NOS (service) & -0.25 & 0.44 & 0.69 & 0.07 & 50.2 \\
\hline AFC (month) & -4.01 & 7.94 & 11.9 & 1.27 & 56.8 \\
\hline BW & -2.77 & 3.34 & 6.11 & 0.68 & 47.2 \\
\hline WW & -2.12 & 1.62 & 3.74 & 0.38 & 33.3 \\
\hline \multicolumn{7}{|c|}{ Multi-trait animal model } \\
\hline 305-dMY (kg) & -4.38 & 7.67 & 12.1 & 1.38 & 55.5 \\
\hline LP (day) & -2.01 & 2.66 & 4.67 & 0.57 & 55.0 \\
\hline NOS (service) & -0.48 & 0.82 & 1.30 & 0.17 & 55.9 \\
\hline AFC (month) & -3.92 & 6.94 & 10.9 & 1.40 & 55.8 \\
\hline
\end{tabular}

\section{Correlations between EBVs from single and multi-trait analyses}

Spearman rank correlations and Pearson correlations between EBVs obtained from single-trait and multi-trait analyses for all animals in the pedigree are presented in Table 7. Correlations between EBVs of all animals in pedigree provided by two genetic analyses ranged between $0.19-0.99$. Rank correlations of animal (sires) between two analyses were lower than the correlations of EBVs and were the lowest for persistency of lactation and reproduction traits. Kadarmideen et al. (2003) and Shalaby (2005) obtained similar results.

Table 7: Spearman rank correlations (below diagonal) and Pearson correlations (above diagonal) among breeding values of different studied traits obtained from single-traits, multi-traits and single-and multi-trait analyses

\begin{tabular}{|c|c|c|c|c|c|c|c|c|c|c|}
\hline \multirow[t]{2}{*}{ Trait } & \multicolumn{6}{|c|}{ Single-traits } & \multicolumn{4}{|c|}{ Multi-traits } \\
\hline & 305dMY & LP & NOS & AFC & BW & WW & 305dMY & LP & NOS & AFC \\
\hline \multicolumn{11}{|c|}{ Single-traits } \\
\hline 305dMY & -- & $0.51^{*}$ & $0.06^{\star *}$ & 0.03 & $0.21^{* *}$ & $0.13^{* *}$ & $0.83^{* *}$ & $-0.15^{\star *}$ & $0.06^{\star *}$ & $-0.05^{*}$ \\
\hline LP & 0.02 & -- & $-0.16^{\star \star}$ & 0.01 & 0.01 & $0.11^{\star \star}$ & $-0.01^{\star \star}$ & $0.50^{\star *}$ & $-0.15^{\star \star}$ & $-0.05^{\star}$ \\
\hline NOS & $0.05^{*}$ & $-0.15^{\star \star}$ & -- & $0.43^{\star \star}$ & $0.05^{\star}$ & $-0.05^{*}$ & $0.20^{\star \star}$ & -0.03 & $0.34^{* *}$ & $0.39^{\star \star}$ \\
\hline AFC & 0.01 & 0.04 & $0.43^{\star \star}$ & -- & $0.08^{* *}$ & $-0.10^{\star *}$ & $0.50^{\star *}$ & $0.75^{\star *}$ & $0.96^{\star \star}$ & $0.96^{* *}$ \\
\hline BW & $0.20^{* *}$ & 0.02 & $0.09^{* *}$ & $0.09^{* *}$ & -- & $0.65^{\star *}$ & $0.23^{\star *}$ & 0.06 & $0.10^{* *}$ & $0.07^{* *}$ \\
\hline WW & $0.09^{* *}$ & 0.03 & $-0.05^{\star}$ & $-0.07^{\star \star}$ & $0.99^{\star *}$ & -- & 0.04 & -0.02 & $0.09^{\star *}$ & $0.09^{\star *}$ \\
\hline \multicolumn{11}{|c|}{ Multi-traits } \\
\hline 305dMY & $0.76^{\star \star}$ & $-0.10^{\star \star}$ & $0.19^{\star \star}$ & $0.49^{\star \star}$ & $0.21^{\star \star}$ & 0.03 & -- & $0.20^{* *}$ & $0.54^{\star *}$ & $0.44^{\star *}$ \\
\hline LP & $-0.12^{\star \star}$ & $0.47^{* *}$ & -0.01 & $0.74^{\star \star}$ & 0.02 & -0.02 & $0.19^{* *}$ & -- & $0.70^{* *}$ & $0.97^{\star *}$ \\
\hline NOS & 0.04 & $-0.11^{\star \star}$ & $0.35^{\star \star}$ & $0.96^{\star \star}$ & $0.21^{\star *}$ & $-0.05^{\star}$ & $0.54^{\star \star}$ & $0.67^{\star \star}$ & -- & $0.99^{\star *}$ \\
\hline AFC & $-0.06^{\star *}$ & -0.02 & $0.30^{\star *}$ & $0.96^{\star \star}$ & $0.08^{\star *}$ & $-0.06^{\star *}$ & $0.44^{* *}$ & $0.77^{\star *}$ & $0.98^{\star *}$ & \\
\hline
\end{tabular}

* Correlation is significant at the 0.05 level.

** Correlation is significant at the 0.01 level. 


\section{CONCLUSION}

It is recommended that selecting for milk production alone would lead to decline in genetic merit for fertility traits considered here, where milk production has antagonistic $r_{G}$ with NOS. Results of genetic correlations suggest that because of single-trait method is biased due to selection for $305-$ $\mathrm{dMY}$, a multiple-trait analysis is recommended for production and reproduction traits if all traits are recorded. The genetic parameters estimated from field test records allow to achieve genetic progress in 305-dMY and AFC of Friesian cattle.

\section{ACKNOWLEDGMENTS}

The author gratefully acknowledge Animal Production Research Institute, Ministry of Agriculture, Egypt for making the data available, and Prof. Dale Van Vleck, Department of Animal Science, University of Nebraska, Lincoln, USA for providing the MTDFREML software and its documents.

\section{REFERENCES}

Abdel-Glil, M.F. (1996). Estimation of genetic parameters and trends for some milk traits in herd of Friesian cows in Egypt. J. Agric. Sci., Mansoura Univ., 21:3479.

Ashmawy, A. A. and K. A. Khalil (1990). Single and multi-trait selection for lactation in Holstein-Friesian cows. Egypt. J. Anim. Prod., 27(2): 171.

Atil, H. and A. S. Khattab (2005a). Use of multiple traits animal model for genetic evaluation of milk yield and age at first calving of Holstein Friesian cattle in Turkey. Pakistan J. Biol. Sci., 8 (1): 114-117.

Atil, H. and A. S. Khattab (2005b). Estimation of genetic trend for productive and reproductive traits of Holstein Friesian cows in Turkey. Pakistan J. Biol. Sci., 8(1): 202-205.

Atil, H.; A. S. Khattab and Laila, Badawy (2005). Genetic parameters of birth and weaning weights for Friesian calves by using an animal model. Arch. Tierz., Dummerstorf, 48 (3): 261-269.

Badawy, Laila and E.Z.M. Oudah (1999). A comparison between two different methods of estimating sire transmitting ability of some milk traits in a herd of Friesian cattle in Egypt., J. Agric., Sci., Mansoura Univ., 24(9): 4613-4624.

Boldman, K. G., L. A. Kriese, L. D. Van Vleck, C. P. Van Tassell, and S. D. Kachman (1995). A manual for use of MTDFREML. USDA, ARS, Clay Center, NE., USA.

Costa, C. N., R. W. Blake, E. J. Pollak, P. A. Oltenacu, R. L. Quaas, and S. R. Searle (2000). Genetic analysis of Holstein cattle populations in Brazil and the United States. J. Dairy Sci. 83(12): 2963-2974. 
El-Arian, M.N.: H.G. El-Awady and A.S. Khattab (2003). Genetic analysis for some productive traits of Holstein-Friesian cows in Egypt through MTDFREML program. Egyptian J. Anim. Prod., 40(2): 99-109.

El-Awady, H.G. and E.Z.M. Oudah (2009). Genetic and economic analysis for the relationship between udder health and milk production traits in Friesian cows. J. Agric. Sci., Mansoura Univ., 34 (8): 8667 - 8685.

El-Sheikh, S.M. (1995). Some productive and reproductive traits of dairy Friesian cows under Sakha condition. Ph.D. Thesis, Fac. Agric., Cairo Univ., Egypt.

Gopal D. and D.S. Bhatnagar (1972). The effect of age at first calving and first lactation yield on lifetime production in Sahiwal cattle. Indian J. Dairy Sci., 25:129-133.

Gröhn, Y. T., J. A. Hertl and J. L. Harman (1994). Effect of early lactation milk yield on reproductive disorders in dairy cows. Am. J. Vet. Res., 55(11): 1521-1528.

Haile-Mariam, M., P. J. Bowman, and M. E. Goddard (2003). Genetic and environmental relationships among calving interval, survival, persistency of milk yield and somatic cell count in dairy cattle. Livest. Prod. Sci., 80: 189-200.

Hammoud, M.H.; S. Z. El-Zarkouny, and E. Z. M. Oudah (2009). Effect of sire, age at first calving, season and year of calving and parity on reproductive performance of Friesian cows under semiarid conditions in Egypt. J, Agric. Sci., Mansoura Univ., 34(7): 7627-7648.

Kadarmideen, H. N., R. Thompson, M. P. Coffey, and M. A. Kossaibati (2003). Genetic parameters and evaluations from single- and multipletrait analysis of dairy cow fertility and milk production. J. Livest. Prod. Sci., 81: 183-195.

Kassab, M.S and A.Y. Salem (1993). Some factors affecting reproductive Efficiency and its relationship with milk production in Friesian cows. Alex. J. Agric. Res., 38: 105-115.

Khattab, A.S.: M.N. El-Arian and H. Atil (2000). Estimation of milk producing ability of Holstein-Friesian cattle in a commercial herd in Egypt. Pakistan J. Biol. Sci., 3: 1076-1079.

Lengyel Z.; Szabo, F.; Komlosi, I. (2001). Effects of year, season, number of calving and sex on weaning performance of Hungarian Simmental beef calves. 52 ${ }^{\text {nd }}$ Annual Meet. European Assoc. for Animal Production. Budapest, Hungary, August 26-29.

Misztal, I, T. J. Lawlor and H. Short (1993). Implementation of single- and multiple-trait animal models for genetic evaluation of Holstein type traits. J. Dairy Sci., 76:1421-1432.

Ojango, J. M. K. and G. E. Pollott (2001). Genetics of milk yield and fertility traits in Holstein-Friesian cattle on large-scale Kenyan farms. J. Anim. Sci., 79(7): 1742-1750.

Oudah, E.Z.M. (2002). Genetic parameters sire evaluation and genetic trends in preweaning growth traits of Friesian calves in Egypt. 7th World Congress on Genetics Applied to Livestock Production, August 19-23, 2002, Montpellier, France (Paper No. 02-72). 
Oudah, E.Z.M. and A.F.A. Mehrez (2000). Genetic and non-genetic factors affecting preweaning body weight and growth rate of Friesian calves raised in Egypt. $3^{\text {rd }}$ All Africa Conference on Animal Agriculture and $11^{\text {th }}$ Conference of the Egyptian Society of Animal Production. 6-9 November 2000. Alexandria, Egypt. PP: 689-695.

Oudah, E.Z.M. and H.G. El-Awady (2006). Selection indexes for genetic improvement of preweaning growth traits in Friesian calves in Egypt. Pakistan J. Biol. Sci., 9(4): 723-728.

Oudah, E.Z.M.: N.A. Shalaby and M.A. Mostafa (2001). Genetic and nongenetic factors affecting days open, number of service per conception and age at first calving in a herd of Holstein-Friesian cattle. Pakistan J. Biol. Sci., 4(6): 740-744.

Pryce, J.E., R. J. Esslemont, R. Thompson, R. F. Veerkamp, M. A. Kossaibati and G. Simm (1998). Estimation of genetic parameters using health, fertility and production data from a management recording system for dairy cattle. Anim. Sci., 66: 577.

Royal, M. D., A. P. F. Flint and J. A. Woolliams (2002). Estimation of genetic and phenotypic associations between endocrine and traditional fertility parameters and production traits in Holstein-Friesian dairy cows. $\mathrm{J}$. Dairy Sci., 85: 958-967.

SAS (2004). Statistical analyses system Institute Inc. 2004. SAS/SAT@ 9.1 user's guide Cary. NC: SAS Institute Inc.

Schaeffer, L. R. (1984). Sire and cow evaluation under multiple trait models. J. Dairy Sci., 67: 1567-1580.

Seykora, A. J., and B. T. McDaniel (1983). Heritability and correlations of lactation yields and fertility for Holsteins. J. Dairy Sci., 66: 1486-1493.

Shalaby, N. A., E. Z. M. Oudah and M. Abdel-Momin (2001). Genetic analysis of some productive and reproductive traits and sire evaluation in imported and locally born Friesian cattle raised in Egypt. Pakistan J. Biol. Sci., 4(7): 893-901.

Shalaby, N.A. (2005). Genetic evaluation for milk production, reproduction traits and persistency of lactation using single- and two-trait animal model analyses for Friesian cows in commercial herds in Egypt. J, Agric. Sci., Mansoura Univ., 30(7): 3637-3654.

SPSS (1999). Statistical Package for Social Statistics, Base 10.0 User's Guide. Chicago, IL: SPSS Inc.

Steinhardt, M. and H.H, Thielscher (2000). Growth and development quality of dairy calves reared in groups with an automatic milk feeder. Physiological variables and their changes at specific age periods. Arch. Tierz., Dummerstorf 43(1): 27-44. 
Oudah, E. Z. M.

\section{تقدير المعايير الوراثية والقيم التربويـة باستخدام التحليل الفردي والمتعدد بنموذج

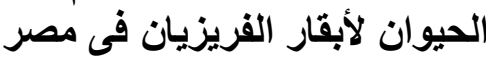

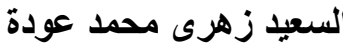
قسم إنتاج الحيوان-كلية الزراعةـ جامعة المنصورة ـ رقم بريدي

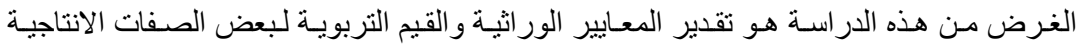

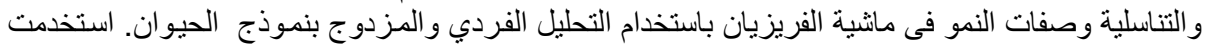

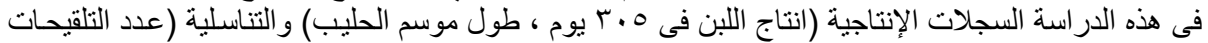

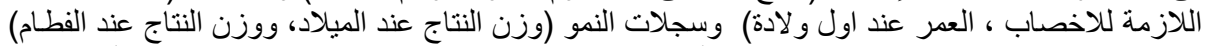

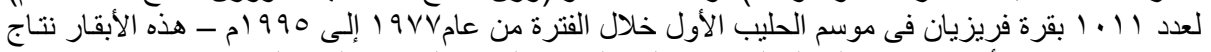

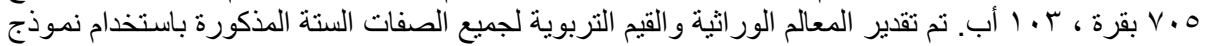

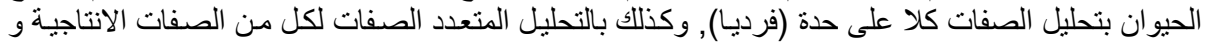

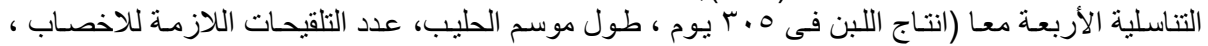

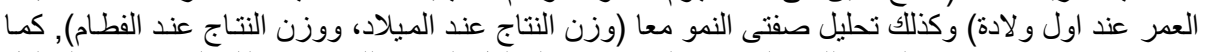

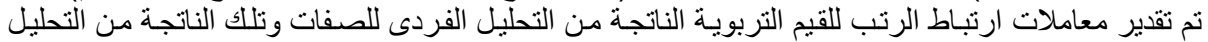

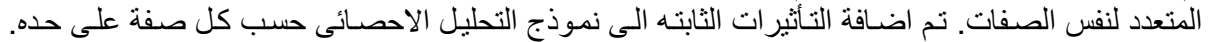

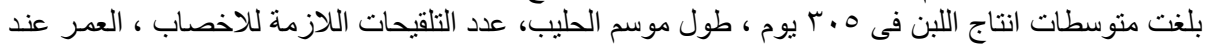

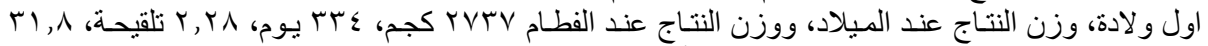

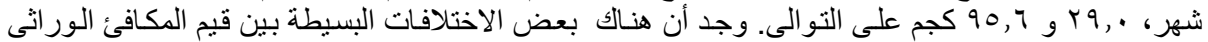

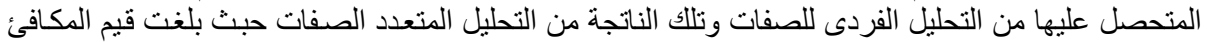

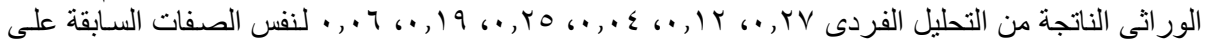

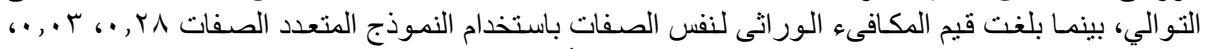

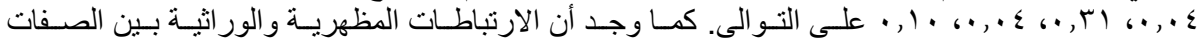

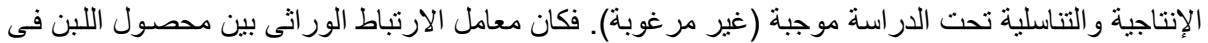

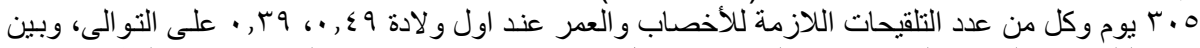

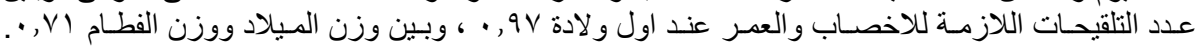

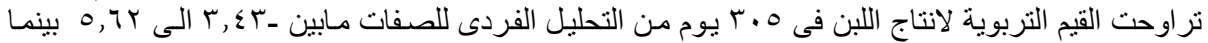

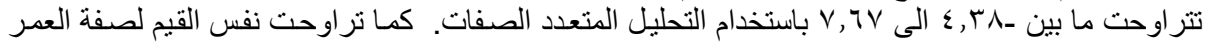

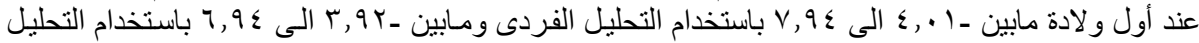

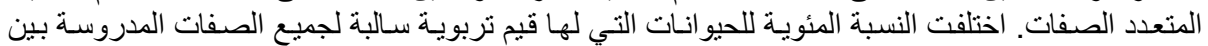

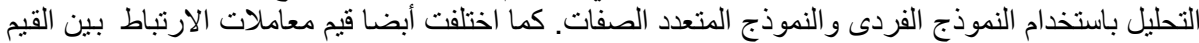

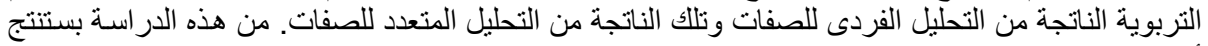

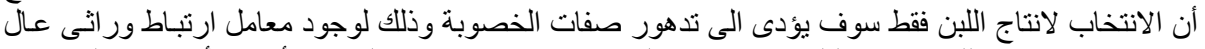

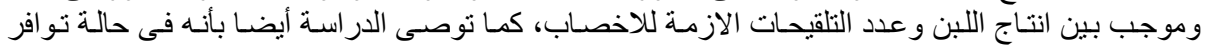

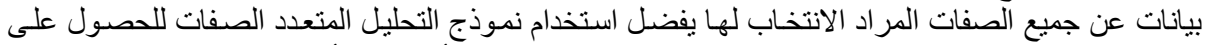

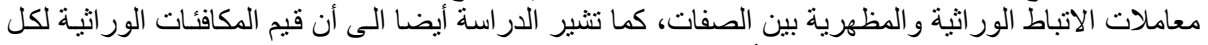

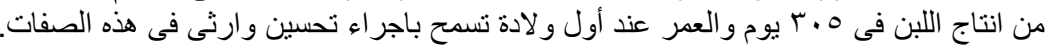

